\title{
Renal Cell Carcinoma in a Renal Allograft Successful Treatment with 5 Year Follow-up
}

\author{
J. Vincent Thomalla, MD, Department of Urology, Marshfield Clinic, Marshfield, Wisconsin
}

\begin{abstract}
Renal cell carcinoma (RCC) developing in a renal allograft either as a result of undetected presence within the donor organ or as a consequence of de novo development post transplantation is a rare event. The Cincinnati Transplant Tumor Registry has recorded 45 cases of RCC developing in a renal allograft. A case is presented of localized RCC developing in a renal allograft 10 years post transplant treated by partial nephrectomy with 5 years of disease-free follow-up.
\end{abstract}

RECEIVED: JUNE 2, 2004

REPRINT REQUESTS:

J. Vincent Thomalla, MD

Department of Urology

Marshfield Clinic

1000 North Oak Avenue

Marshfield, WI 54449

Telephone: $715-387-5235$

Fax: 715-389-3808

Email: thomalla.j.vincent@marshfieldclinic.org
REVISED AND ACCEPTED: JULY 13, 2004

KEYWORDS:

Transplantation, homologous;

Kidney neoplasms; Nephrectomy, methods 


\section{INTRODUCTION}

Localized renal cell carcinoma (RCC) within a renal allograft is rare. The Cincinnati Transplant Tumor Registry has recorded 45 cases of RCC developing in a renal allograft. ${ }^{1}$ A safe and effective treatment with minimal potential for recurrent or metastatic disease is partial nephrectomy. Here, a case is reported of a 31-year-old female who was treated by partial nephrectomy for localized RCC developing in a renal allograft 10 years post-transplant. Five years of follow-up chest X-rays and abdominal computerized tomography (CT) scans have revealed no evidence of local or metastatic spread.

\section{CASE REPORT}

A 31-year-old female who had undergone a haplotype matched, living-related transplant 10 years previously for renal failure associated with a neuropathic bladder presented for evaluation of microscopic hematuria. An intravenous pyelogram demonstrated a $3.8 \times 4.2 \mathrm{~cm}$ mass lesion in the upper pole of the allograft, confirmed as solid by CT (figure 1). The lesion appeared localized without evidence of metastatic spread as determined by CT scanning of the chest, abdomen, and pelvis. Fine needle aspiration of the mass revealed cells consistent with a low-grade RCC. After discussing options for management with the patient, it was decided to pursue partial nephrectomy without interruption of immunosuppression, consisting of cyclosporine, $300 \mathrm{mg}$ daily (200 mg every morning, $100 \mathrm{mg}$ every evening), and azathioprine, $150 \mathrm{mg}$ daily. The patient had never received corticosteroids post-transplantation. Ultrasonographic evaluation of the donor's remaining kidney revealed no evidence of cystic or solid lesions.

A transabdominal approach was utilized because of the intra-abdominal placement of the graft. The kidney was completely mobilized to allow for avascular hypothermic resection of the tumor with a margin of normal renal parenchyma. The defect was closed primarily over a large thrombin impregnated absorbable gelatin sponge after smaller parenchymal vessels were oversewn. Frozen section was not utilized as the lesion was completely resected. Prior to cross clamping, the patient was started on dopamine, $2 \mu \mathrm{g} / \mathrm{kg} / \mathrm{min}$, and was given $20 \mathrm{~g}$ of mannitol.

Heparinization was utilized and reversed. Total clamp time was 15 minutes. No drains were placed postoperatively. Final pathology revealed a well-differentiated, papillary RCC grade I/III with negative margins (T1N0M0). The postoperative course was uneventful with immediate allograft function and maintenance of the preoperative baseline creatinine of $1.2 \mathrm{mg} / \mathrm{dl}(0.3$ to $1.1 \mathrm{mg} / \mathrm{dl})$. Postoperative abdominal CT scans and chest X-rays at 7, 22, 31 , and 57 months have revealed no evidence of local or metastatic spread (figure 2). The patient's current creatinine is $1.5 \mathrm{mg} / \mathrm{dl}$ on an immunosuppressive regimen of cyclosporine, $175 \mathrm{mg}$ bid, and azathioprine, $50 \mathrm{mg}$ daily.

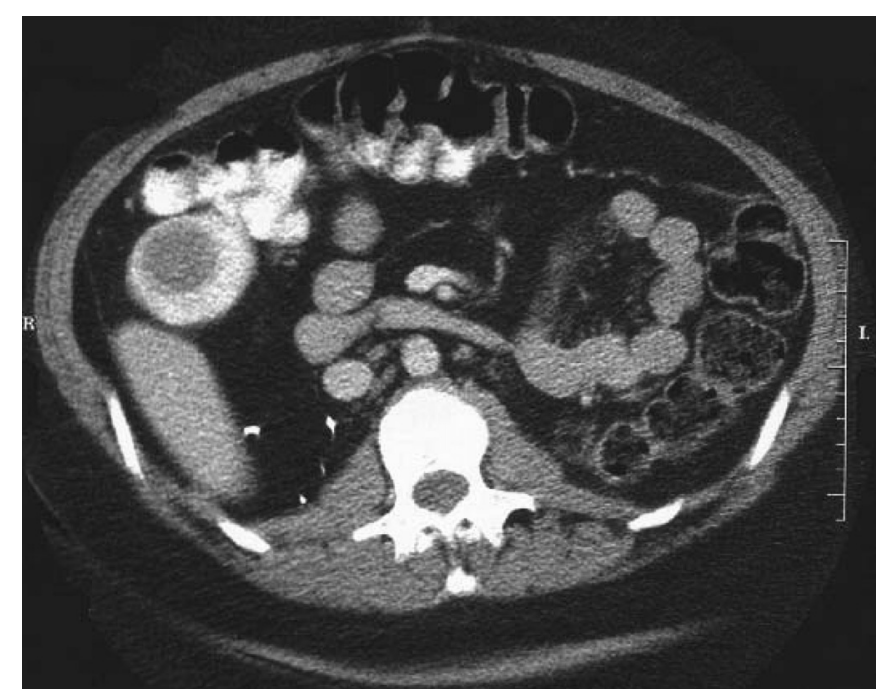

Figure 1. Renal mass appearing in the superior lateral aspect of the intra-abdominal graft.

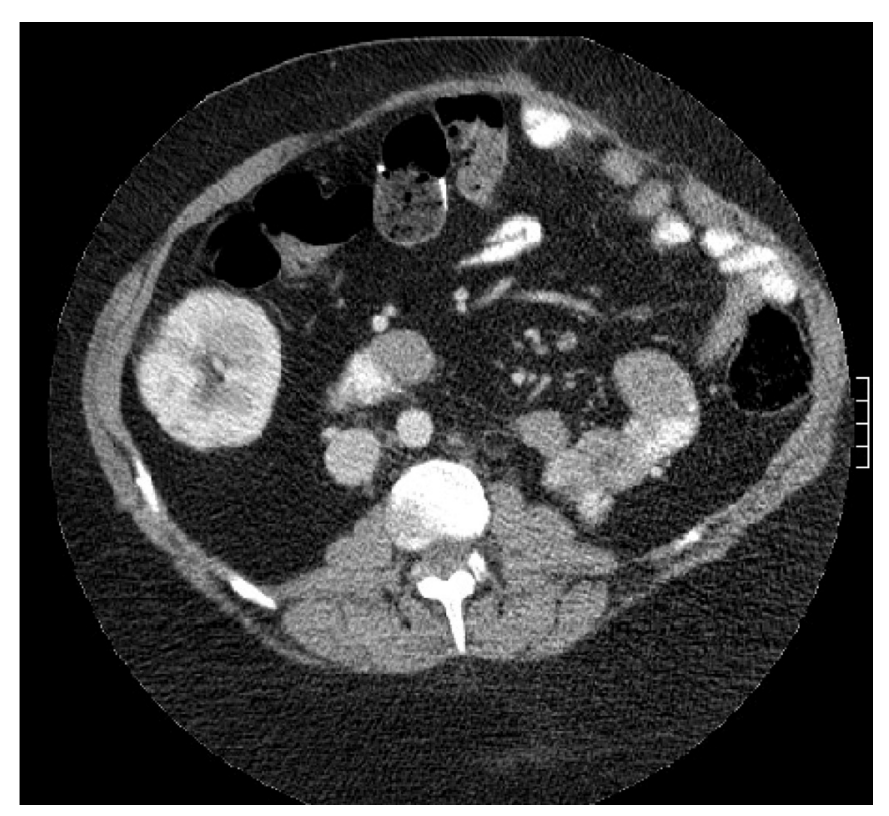

Figure 2. Resection site 51 months postoperatively with no evidence of recurrence.

\section{DISCUSSION}

Although rare, renal transplant recipients who develop RCC in their graft present a unique dilemma because if a conservative approach were chosen to preserve their graft, it may place the patient at great risk for developing fatal metastatic disease as a result of immune incompetence. Historically, the graft would be sacrificed with the patient placed back on dialysis and offered re-transplantation, if appropriate, after a 2-year waiting period. Recent clinical experience with partial nephrectomy for RCC in non-transplant patients has demonstrated this technique to be a highly effective means of treating localized RCC with minimal risk for recurrence or development of metastatic disease with very acceptable operative risk. ${ }^{2,3}$ The indication 
for partial nephrectomy for RCC continues to encompass a growing patient pool as more experience is gained with traditional as well as newer and less invasive technologies (e.g., cryotherapy, radio frequency ablation). Recent reports demonstrate that localized RCC within a renal allograft can be safely and effectively treated by partial nephrectomy with minimal potential for recurrent or metastatic disease. ${ }^{4}$ This case report contributes to a growing body of evidence demonstrating the effectiveness and desirability of partial nephrectomy for the management of RCC.

\section{ACKNOWLEDGMENTS}

The author thanks Marshfield Clinic Research Foundation for its support through the assistance of Linda Weis, Jennifer Hayes, and Alice Stargardt in the preparation of this manuscript and Pam Mundt for data collection.

\section{REFERENCES}

1. Penn I. Cancers in renal transplant recipients. Adv Ren Replace Ther 2000;7:147-156.

2. Thomalla JV. Nephron-sparing radical renal surgery for malignant renal tumors. Marshfield Clinic Journal 2000;1:21-29.

3. Lerner SE, Hawkins CA, Blute ML, Grabner A, Wollan PC, Eickholt JT, Zincke H. Disease outcome in patients with low stage renal cell carcinoma treated with nephron sparing or radical surgery. J Urol 1996;155:1868-1873.

4. Kim JY, Ruckle HC, Ramin SA. Partial nephrectomy for renal cell carcinoma in an allograft kidney 15 years after transplantation. J Urol 2001;165:1205. 